\title{
In Search of Professionalism, Bureaucracy and Sustainable Livelihoods for the 21st Century
}

\author{
Robert Chambers
}

\section{Overview}

This article argues that in the 21 st century livelihoods will be needed for vastly more people, many of them in marginal and fragile rural environments. To enable more of these livelihoods to be sustainable requires outsiders to reverse much that is normal in professionalism, bureaucracy, careers, and learning; to recognise that livelihoods are often complex and diverse; to decentralise; to deregulate and free poor people from hassle and rents; to make their rights more secure; to provide better access to services; and through all these to help poor rural people to take the long view. Normal prescriptions are for changes in structures, laws and procedures rather than in behaviour or methods. But recent experience has indicated that when outsiders behave differently and use new participatory methods, poor rural people show an unexpected creativity and capacity to present and analyse information, to diagnose and to plan. They know the complexity and diversity of their conditions and livelihoods, on which they are up-todate experts. To provide conditions for more sustainable rural livelihoods for the 21 st century, one frontier for the 1990s is methodological R \& D. This is to find better ways of enabling professionals and officials to change their behaviour and attitudes, and to learn from and to empower rural people.

\section{Sustainable Livelihoods for the 21st Century}

The context is stark. Population projections for the 21 st century have risen. Over the 37 year period 1988 to 2025 , both the populations of low income countries, and those of middle income countries, are projected to rise by 80 per cent (for these and other estimates, see WDR 1990: 228-9 and 338-9). Taking only the low income countries, the increase has been estimated at 2.3 billion, from 2.9 billion to 5.2 billion. In most if not all of these countries, it seems inescapable that rural as well as urban areas will have to support many more people.

Considering sub-Saharan Africa (SSA) alone, population is estimated to treble in the next 40 years. In round figures for the period 1988 to 2025 , even if the current urban population of 130 million were to grow fivefold to 650 million by 2025 , the rural population would still have to double, from 330 als: : 0650 million. In SSA, as elsewhere, the larger the nu-mer of people who can find their living in rural aree: - je less will be the pressure on the towns and cities.

At the same time, in low and middle in:me countries, the exploitation of rural resources is already often unsustainable, and least sustainable it- those regions, countries and zones with the lowest uranisation, the highest population growth rates. $z-\mathrm{d}$ the most vulnerable rural environments. An strategy for environment and development for $t=21$ st century which is concerned with people, equity and sustainability has, then, to confront te question of how a vastly larger number of people basically decent rural livelihoods in $\approx$ zanner which can be sustained, many of them in envir.zments which are fragile and marginal.

This has two linked dimensions. Some Lustainability results from the greed and shortsight the rich and purerful, including professionals ant $=$ bureaucrais. The solution here is a battery of $\pi$ Essures and of countervailing forces to change the bizaviour of the rich and powerful. Some unsustainab- also results from the survival strategies of the pos.- The solution here is empowering the poor in a =anner which encourages and enables them to take $i=$ long view, to enhance and not degrade resources $a-i$ to resist the rich and powerful. This paper explor some ways in which these conditions can be achiered, including some recent developments in Sow Asia, and concludes that methodological $R \& D$ provides one key to change.

\section{The Normal as Problem}

A prudent start is to examine oursel $=$. as observers and developers of 'them', and some of the normal errors associated with our professior $\equiv$ ism, bureaucracy, (successful) careers, and styies of learning. These are usually regarded as part of tie solution. The argument here is that they are much on the problem.

Normal professionalism, meaning the concepts, values, methods and behaviour dominant in professions, tends to put things before people. men before women, the rich before the poor, anc the urban and industrial before the rural and agricut-iral. It values and uses measurement more than dgement, and 
methods which are often reductionist, simplifying the view of complex reality.

Bureaucracy as normally found is hierarchical and tends to centralise, standardise and regulate. Field bureaucracies in the South of ten extract rents from the poor by exploiting rules and regulations, and demanding payments for services rendered or penalties not inflicted. Bureaucrats' time horizons are usually short, bounded by targets for the financial year.

Normal (successful) careers related to rural life often start in the periphery and then move upwards in hierarchies and inwards to larger and larger urban centres. Those who end up in powerful policy positions tend to be ageing men whose direct personal experience of rural conditions is variously nonexistent, biased, and out-of-date.

Finally, normal learning is from 'above', from teachers, books, and urban centres of knowledge, and not from 'below'. from rural people, let alone in a shared manner with them.

These four forms of normality interlock and reinforce each other. They tend to centralise, standardise. simplify, and regulate. to seek to transfer standard technology from controlleci to uncontrolled conditions. to have short time horizons, and to be out-of-date. They fit the much discredited but widely practised blueprint model for human development, planned from the top down.

Most of these points are now accepted among enlightened development academics and practitioners, but some reasons for their misfit with the conditions and needs of poor people and vulnerable environments, and some implications of those reasons, are less fully appreciated.

\section{Complexity and Diversity Underperceived}

Complexity and diversity are dimensions of the livelihood strategies of many of the poor. Some do adopt specialised strateg:es which rely on a single activity or source of supfort, but most are versatile and opportunist. Different members of households do different things at different times of the year. They cultivate, herd, undertake casual labour, make things to sell, hawk and trade, hunt and gather a multiplicity of common property resources, and migrate for seasonal work. They bond their labour, beg, borrow and sometimes steal. Moreover, it is often by diversifying their livelihoods, especially in slack seasons [Agarwal 1989], that poor people try to do better, reducing risk with fallback activities.

In agriculture, where topography is uneven and rainfall irregular, farming systems are made more stable and sustainable not by standardising through adopting uniform packages of practices generated by normal research, but by diversifying, complicating, and intensifying activities.

Diversity and complication take many forms. Seeds are stored not of one crop variety, but the several; and what is planted depends on how each season unfolds, the form and fertility of each field and part of a field. and the household's members" evolving needs and priorities. In 1991. a rainfed rillage in South Bihar in India was found to be growing 28 varieties of paddy [R. Jayakaran pers. comm.]. Mixed cropping, and multiple canopies. in their many forms, spread production and reduce risk. A Lousehold seeks to rear not one type of animal but a portfolio of different domestic livestock species. As common property resources diminish, with a loss of diversity, so farmers re-establish sources of their products on their own land, as with planting trees cor timber, fuelwood, fodder and other needs on private farmland in Kenya [Bradley, Chavangi and Van GElder 1985] and Nepal [Carter and Gilmour 1989]. Furiner complications are introduced through adding io internal linkages. Nutrient flows are multiplied to provide redundancy: if one source of fodder fails. Others are there as fallback [Chambers 1990b].

Intensification is found in microenvironments. These provide a pertinent illustration for the 21 st century. As population to land ratios rise. so farmers intensify their systems. In many wars. depending on local conditions, they variously create, protect and exploit microenvironments. These include sirips and pockets of fertility, ponds. hedges. groves, agroforestry in its many forms, flood recession zones, small flood plains, patches of irrigation. home ga-dens, terraces, valley bottoms, wet and dry watercourses, springs and zones of seepage.

An example in semiarid conditions is deposition fields, found widely in India and Ce-rial America [Wilken 1987:70-71] and also Ethiopic [ECRS 1988:36-37]. These are formed of silt trapped by barriers of large stones. Farmers invest their lajour in building these up progressively over the yeass. Deposition fields harvest and concentrate soil. water and nutrients. and are often protected from winc and sun by the gully walls, providing conditions in which higher value crops (such as coffee. chat and papaya in Ethiopia, and rice in India) are grown than in the drier and less fertile conditions of surrounding fields.

An example more common in subhumid conditions is aquaculture, where a fish pond establishes many nutrient linkages with other elements in a farming system, with fish consuming crop residues. animal manure, and leaves and with fish manure in turn contributing to field fertility.

Most deposition fields and fish ponds alike are human made, created partly in response to population pressures. By concentrating resources, stabilising environmental conditions. and multiplying enterprises, 
linkages and outputs, they support more substantial and sustainable livelihoods; and they do this not by simplifying and standardising as in industrial and green revolution agriculture, but by complicating and diversifying.

The complexity and diversity of many rural livelihoods and of much resource-poor farming are, however. systemically underperceived and underestimated by outsider professionals. Rural development tourism - the brief rural visit by the urbanbased professional - gives a single snapshot view at one point in time (and one time of the day), and is too rushed to see or learn more than the obvious. Survey questionnaires perpetuate reductionist ignorance, with their categories preset and confined to what the compiler knew to ask about, and with their incentives to investigators and respondents to keep answers simple and short so as to finish sooner. Normal professionals focus on large livestock, cash crops, and major food crops to the neglect of multiple sources of subsistence. Many practices of the poor fall outside the normal purview of specialists, for example as Beck [1989] has shown, the share-rearing of livestock and the use of common property resources, both of which are widespread sources of livelihood for the poor across countries, regions and continents. Many of the activities of women are unseen by outsiders who work on rural development, most of whom are men. Microenvironments are $c$ ften unobserved, either tucked away in valley bottoms, o like homegardens unnoticed because they are small, untidily diverse, and the concern of women [Chambers 1990a].

Finally, there is a normal bureaucratic and professional preference for standard programmes which are the same everywhere. These can be described as 'Model Ts' after Henry Ford's famous remark that people could have their Model T Ford automobile any colour they liked as long as it was black. Model T programmes focus attention on a single externally introduced element in livelihoods, at the cost of recognition of the many others on which people also rely. Subject to so many distortions of view, it is difficult for planners and policymakers to appreciate and support the complexity and diversity of the livelihood strategies of many of the rural poor.

\section{For the Poor to Take the Long View}

A common belief is that while professionals take a long-term view of sustainability, poor rural people live 'hand-to-mouth' and take a short-term view. Often, the opposite is true.

Many of those who take a short-term view, unconcerned with sustainability, are powerful outsiders - politicians, contractors and businessmen, bureaucrats, and economists. Politicians in democracies focus their foresight as far as the next election.
Contractors and businessmen mine minerals, quetry rocks, cut out timber concessions, and overgraze pasture, all for immediate profit. Bureaucrats borand by targets for the financial year or the project period, and subject to transfers at short notice, focus on a future of months rather than years, still less decades. For their part, economists, despite the revolution of environmental economics, still discount the futur $\approx$ as they practice conventional cost-benefit anaizisis. Future historians of human folly may well look cack with wonder at the resilient inertia of discountir the late 20th century. For in an age when the environment and sustainability are part of the resalar rhetoric, discounting undervalues the future. contradicting common sense and common responsibrity for a sustainable development for future generations. So it is outsiders - their politics, their profits and toeir sometimes purblind professionalism - who. cnce again, are much of the problem.

In contrast, and contrary to common professional prejudice, poor rural people often want to take the long view. When desperate, they do indeed have to live 'hand-to-mouth'. But to take a long-term view. and to invest for sustainable livelihoods, they need secure rights to resources, and secure access to services.

When poor people have secure rights to resources, they often behave in ways which manifest a long view: they create, protect and develop microenvironments, like terraces and structures to capture and concentrate soil, water and nutrients; they plant and protect trees which they will never live to harvest. In adversity it is with formidable tenacity that they cling onto taeir land and other productive assets [Corbett I988; Agarwal 1989:51]. Where conditions permit. the means for sustainable livelihoods are evident $I_{z}$ a priority for them. And where communities have seonre control of common resources, they often manage responsibly and equitably. It is rural people. assin, who are much of the solution.

In practice, incentives to take the long view are diminished by restrictions, hassle and consequent insecurity. Hassling the poor and extracting rents are widespread. An analysis [Davies, David and Leach 1991:34-5] of six environmental scenarios posited restricted access. and fines for malpractice. as alpost universal aspects of policy options which would adversely affect food security. Draconian bureauctatic rules to protect the environment regularly ruin it and penalise the poor by making their rights insecure by inhibiting investment, and by inducing short-term exploitation as people take what they can while they can.

Access to services, such as health and credit, are other dimensions of sustainable livelihoods: health to maintain the ability to work, and credit for investment or to tide over bad times. Here rents and rudeoess impede access. One of the findings of the United 
Nations University programme on Rapid Assessment Procedures for primary health care in some 18 countries was that 'rudeness on the part of government health services staff was a deterrent to the use of services in most of the communities studied' [Scrimshaw and Hurtado 1987:2]. Obtaining services which are meant to be free or easily available regularly requires payment of rents - whether the services are medical, legal. credit, permits, licences, passes or the like. Access for the poor is all too often restricted. and insecure, risky, and costly in time and cash.

\section{Reversals as Solutions}

The question is how to diminish and overcome these misfits between what normal professionals and bureaucrats perceive and do, and what poor rural people need for sustainable livelihoods: between top down. standardised, simplified, regulated, rigid and short-term blueprinting, and local-level diversified, complicating, unregulated, flexible, and long-term processes.

Solutions can be sought through reversals, through turning the normal on its head. Professionally, this means putting people before things. the poor before the rich, and women and children before men and adults, with the girl child first of all. It means permitting and promoting the complexity and diversity that poor people often want, presenting :her: with a basket of choices rather than a package of practices. Bureaucratically, it means decentralising power. destandardising, and removing restrictions. In careers, it means not just moving with promotions inwards to larger urban centres, but also moving with sabbaticals outwards to revisit and reappraise rapidly changing rural realities. In learning. it means gaining insight less from 'our' often out-of-date knowledge in books and lectures, and more from 'their' knowledge of their livelihoods and conditions which is always up-to-date; less from rural development tourism. and more from relaxed and participatory appraisal: and less from questionnaire surveys, measurement and statistics, and more from participatory learning methods, ranking and scoring. In behaviour, it means the most important reversal of all, not standing, lecturing and motivating, but sitting, listening and learning. And with all these reversals, the argument is not for an absolute or 'slot-rattling' change, from one extreme to another; rather it is that only with a big shift of weight can an optimal balance be achieved.

Such reversals may appear the fantasy wish list of an unreconstructed idealist. In practice, however, many changes in the direction of these reversals have occurred and are gaining momentum. In India, for example, decentralisation, destandardisation, and deregulation have been taking place across a range of departmental activities. In canal irrigation, standard programmes for all projects have gradually been supplemented by individual operational plans for each system. In social forestry, many more species are now available in forest nurseries, proviong a choice to farmers, than five years ago, and there are moves to reduce restrictions on harvesting tres on private land. In watershed development, universal solutions through the same technology everthere have been widely questioned; and in agricuitu-al research, the concept of the basket of choices -ather than the package of practices for rainfed tamers is gaining ground.

With any shift of balance between $=E-$ digms, as with such reversals, there are severa! cimensions and several levels for action and pressce. The normal reflexes of reformers are activist. or $\subseteq$ isational, legal and procedural: activist reformers $5=2 k$ to mobilise pressure groups, in this case ruz groups and communities, to protect and demare their rights to resources and to access to servicers organisational reformers seek to create new organisations or departments, or to change their intenal shape; legal reformers seek to change the law as land reforms; and procedural reformers seek to change the way things are done within organisaziors. All these are valid, useful and needed.

But all these neglect two aspecs: the knowledge, creativity and competence of rura! people in appraisal and analysis, and in gaining and sustaining their livelihoods; and the primacy of ontiders' behaviour and attitudes in enabling that reativity and competence to be expressed.

\section{The Knowledge, Creativity and Competence of Rural People}

The potential for reversals is indicere by experiences in SSA and most recently in Souiti Asia (India and Nepal) with the evolution of rapic zural appraisal (RRA) [KKU 1987] and agroesos:siem analysis [Conway 1985] into relaxed and pa-ijipatory rural appraisal (PRA). This has show have capabilities which few outsicers. apart from a handful of social anthropologists. $\approx-$ have suspected [IIED 1988-; PRA/PALM 1990-]. These are capabilities for mapping and modelling [Mescarenhas and Kumar 1991], transects and obserwation, ranking, scoring, quantifying, seasonal ancisis. casual and linkage diagramming [Lightfoot 199.]. interviewing others, analysis, and planning. A mass of experience has been gained, but developments have been so rapid that only a small fraction has been reported in an accessible form. One major finding has been that participatory appraisal methods in $\approx$ sharing mode present more complex and diverse information and insight than do traditional "extractise' methods of investigation, and do so in much less zime. 
For the expression of people's knowledge and creativity in these ways, conditions have to be favourable. In the past, this has been rare. Four conditions are predisposing, if not essential: rapport where the outsider shows humility, respect and interest in learning from rural people; restraint in not interrupting or over-interviewing: the use of participatory methods; and appropriate often local materials for mapping, modelling. ranking. scoring. diagramming and analysis.

When these conditions have been achieved, people have shown themselves capable of presenting, checking, analysing and enhancing their knowledge in ways which have exceeded expectations and sometimes astonished. Rural people often have extensive and detailed knowledge. In contrast with the reductionism of some standard science, they can show a mastery of complex detail and an ability to identify multiple criteria and then to score, rank and weigh them. The puzzle is how we and they have failed to realise and express all this earlier. Part of the explanation may lie in the arcane, esoteric and inbred communications of some anthropologists, who have had hints of this and known parts of it but not realised or shared its significance and potential. In part, too, explanations can be sought in outsiders' norma! behaviour which is lecturing and not listening, confident in the superiority of their knowledge and technologies for transfer. Outsiders' attitudes and behaviour have induced rural peorle to present themselves ieferentially as igmorant and incapable. Their supposed ignorance and incapability have then been as artifact of our selfvalidating attitudes and behaviour.

\section{The Primacy of Personal Behaviour}

Regarded historically, the neglect of personal attitudes and behaviour has been a stunning oversight in rural development practice. Training, attitudinal change, skill acquisition, 'motivation' -- all these have been for 'them', for rural people, more than for 'us', the professional elites. Yet since we are so often the dominant actors, our attitudes and behaviour are primary: what we do largely determines what a new organisational structure achieves. whether and how laws are enforced, whether and how procedures are implemented, and now above all, how fully and freely poor people participate in appraisal, analysis and action. This being so, it is curious that, outside of education, psychologists are still such a rare profession in development; and that only occasionally does professional training confront questions of personal perceptions, orientation and behaviour. Such past neglect makes methods and behaviour even stronger points of entry for change.

One quick approach is to confront professionals' attitudes and behaviour head-on through role plays, videos, games and mutual observation and checking. Another is to teach them methods which give experiences which in turn change their perceptions and values. Whatever combination is followed. practical approaches and methods include: correcting behaviour such as lecturing to villagers e.g. by tapping outsiders' shoulders when they err [Anil C. Shah pers. comm.]; outsiders undertaking village tasks as students, with villagers as teachers; matrix ranking and scoring in which the procedure forces the outsider to elicit the criteria and judgements of the villager; and temporary total immersion in village conditions, as stressed in training in India p:oneered by NGOs such as MYRADA, Action Aid. and others.

Powerful and popular as PR.A methods are, they have spread spontaneously, and in India and Nepal have led to many demands from goverament organisations for training. Obvious dangers loom - of over-rapid adoption, of the label spreacing without the essence. of discrediting and disillusion through misuse. One hope is that critical self-awareness, embracing error, and the one sentence manual of Nordstrom 'Use your own best judgement at all times" [Peters 1987:378], will build quality assurance and improvement into the very genes of PRA. It is too early to know how well this will work, or what is the full poter:ial of these approaches and methods, but much experience has been positive. And beyond applications of PRA itself, the spin-offs of at + itude and beharioural change should strengthen other reform.s, whether structural, lega! or procedural.

\section{R \& D for a Methodological Revolution}

In the search for professionelism, bureaucracy, and sustainable livelihoods for the 21 st century, the needed revolution is, then. more 'ours' than 'theirs'. It entails reversals in professionalism. bureaucracy, careers and learning. It fits and supports a paradigm for future society and development which values the three Ds decentralisation. diversity. and democracy - a pattern discussed and sought increasingly in the North as well as in the South. Potertial paths towards such conditions are many. In rura! development new ones are being opened up. To explore them rapidly requires new approaches and methocs and therefore R \& D which is consciously methodological.

Surprisingly, though, methodological R \& D has been a Cinderella in the protessionalism of rural development. To be sure, the better writing on participation has been concerned with approach and methods [e.g. Korten 1981]: and there have been sustained sequences of innovation, such as the evolution of agroecosystem analysis at the University of Chiang Mai in Thailand and elsewhere [Gypmantasimi et al 1980: Conway 1985], and the pioneering and institutionalisation of RRA at the University of Khon Kaen. slso in Thailand [KKU 
1987]. But generally, research has been thought of as finding out about things (a university activity), development as doing (a government and NGO field agency activity), and $\mathrm{R} \& \mathrm{D}$ as developing physical or biological technology (a laboratory, workshop or research station activity) rather than developing the software technology of methods for personal face-toface interactions between outsiders and rural people.

The pioneers who have recently stepped into this gap and begun to overcome this neglect have been NGOs. Given the stifling intellectual conservatism in many universities, and the stolid procedural conservatism in many field bureaucracies, the principal centres of innovation may well remain for the time being in the NGO sector. An example is the International Institute for Environment and Development (IIED) which has played a major part in developing and legitimating agroecosystem analysis, RRA and PRA. The IIED is an institution in the North, but increasingly, as in India, it will be Southern NGOs that take the lead. The model of $R \& D$ that serves best may well itself be decentralised, diverse and democratic, encouraging many flowers to bloom. There will then be key roles in assessing. recording and communicating experience, in exchanges of persons. between NGOs, and in training. While Northern NGOs will have a support role, the biggest opportunity and challenge will be changes in the South, and especially in government field bureaucracies such as agriculture, forestry, and health.

For sustainable rural livelihoods in the 21 st century, such participatory approaches and methods, whatever their labels, seem essential. Faced with the enormity of the human and environmental challenge, vision is vital. PRA, it has to be said again and again, is no panacea. and is only one label for one part of a pervasive tide of change. But, however modestly, it does open up one path to a better life for poor rural people, by encouraging them to express their knowledge and creativity and to conduct their own analysis; by giving them the ownership of more of the plans and action; by enhancing their confidence and competence; and through all these contributing to sustainable livelihoods by adding to local complexity, diversity, and intensification.

For enabling future sustainable livelihoods, though, ways of changing the attitudes and behaviour of professionals and bureaucrats remain the crux. At a time of questioning professional values, and of accelerating personal and professional change, methodological $R \& D$ still attracts only a minuscule proportion of development professionals; but that itself may change, as more and more realise the potential and excitement of the field. Indeed, change may soon be so fast that methodologically, the 1990 s will be a seminal period which sets patterns for much of the 21 st century. Robert Rhoades [1990] has written about the coming revolution in rural Jevelopment research. But what is needed and may se coming is more than that: a revolution not just in research, but in ways of changing professionals persora values and behaviour.

\section{References}

Agarwal. B.. 1989. 'Social security and to family in rural India' $D E P$ No. 21, The Developmes Economics Research Programme, London Schot Economics, September

Beck. T.. 1989. 'Survival strategies and pon amongst the poorest in a West Bengal village". IDS-Eu- 'tin. Vol. 20. No. 2, April. 23-32

Bradley. P. N.. Chavangi, N. and Var Gaiter. A.. 1985, 'Development research and energy pientos in Kenya', Ambio. Vol. 14. No. 4-5, 228-236

Carter, A. S. and Gilmour, D. A., 1989. 'T Tee cover increases on private land in central Nepal', Mouric:- Research and Development. Vol. 4, 381-391

Chambers. R.. (ed.). 1989, 'Vulnerabilit: Fou the Poor Cope'. IDS Bulletin. Vol. 20, No. 2. Briginter

-1990a. 'Microenvironments Unobse-r.e-'Gatekeeper Series. IJo. 22. International Institute fo: Enswonment and Development. London

-1990b. 'Complexity, diversity and compes =Jce: tuwards sustainable livelihoods from farming sy:es i i the 21st century'. paper for the 1990 Asian $=z-i n g$ Systems Research and Extension Symposium. Be-zi.ti. November

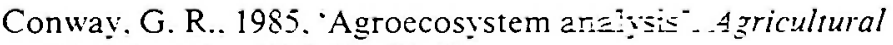
Administrarion. Vol. 20, 31-55

Corbett. J.. 1988. 'Famine and household cogr-at strategies', World Development. Vol. 16, No. 9. 10y-ii:z

Davies, S., David. R. and Leach. M.. 19991. 'Food Security and the Environment: Conflict or Compiementarity?, IDS Discussion Paper 285, Brighton, A־-i

ECRS. 1388. Rapid Rural Appraisal: a Cisser I wir. al Rural Jife in Wollo, Ethiopian Red Cross Society. Addus Ababa and International Institute for Environment $\triangleq n d$ Develspment, London

Gypmantasimi, P.. et al. and G. Conway. 1980. An Interdisciplinary Perspective of Cropping Systems in the Chiang Mai Valley: Key Questions for Researcr. Fandry of Agriculture, University of Chiang Mai. Thanlenc

IIED, 1988-, RRA Notes 1-13 continuing. arailaj]e free from International Institute for Environment and Development, 3 Endsleigh Street, London WCIH ODD

KKU, 1987, Proceedings of the 1985 Intermarional Conference on Rapid Rural Appraisal, Rural Systems Research and Farming Systems Research Projects, Khon Kaeo University, Khon Kaen. Thailand 
Korten. F., 1981, 'Community participation: a management perspective on obstacles and options', in David C. Korten and Felipe B. Alfonso (eds.), Bureaucracy and the Poor: Closing the Gap, McGraw-Hill International Book Company. Singapore. pp 181-200

Lightfoot. C.. 1990. 'Farmer-based methods: farmers' diagrams ior improving methods of experimental design in integratec farming systems', paper presented at the 10th Annua! - FSRE Symposium. October 14-1-. Michigan State Linitorsity. LISA

Mascarenhas. J. and Prem Kumar. P. D.. 1991. 'Participatory mapping and modelling: a user's note". mimeo, MYRAD $\therefore$. 2 Service Road. Domlur Layout. Bangalore 560071 . India

Peters. T.. :987. Thriving on Chaos, (Pan Books edition 1989). Alt: $=d$ Knopf. USA
PRA/PALM, 1990-. Participaror: Learning Methods Series 1-5 continuing. available free from MYRADA, 2 Service Road. Domlur Layout. Bangalor $\$ \$ 60071$. India

Rhoades, R., 1990. 'The coming resolution in methods for rural development research". L " (UPWARD). International Pota: Centre. Box 933. Manila

Scrimshaw, S. and Hurtado. E.. Tapid Assessment Procedures for Vutrition and P-..- Selth Care anthropological approaches to improving z-amme effectiveness. UNU Tokyo. UNICEF and Centre Publications. Linivers, if California, Los Angeles

WDR, 1990, World Deselopmer: :- port 1990. Oxford University Press for the World B

Wilken. G. C.. 1987. Gond Farmer- Treditional Agricultural Resource Management in .Mexis: =nd Central America. University of California Press. Br:-,: $=$ ey and Los Angeles
Print run:2,600. Distribution: worldwide. Sent free to selected Third World institutions. Published: January, April, July, October. Camera-ready copy advertisements needed one month prior to publication date.

Advertising rates: full page $£ 125$. Half page £65. Leaflet for enclosures £45 per 1,000. 105 discount on three or more sequential advertisements in the IDS Bulletin. $25 \%$ discount on IDS Bulletin advertisements or inserts featuring books by IDS authors. Exchange advertising by arrangement.

Technical specifications: Full Page 200 $\mathrm{mm}$ deep $\times 150 \mathrm{~mm}$. Half page $100 \mathrm{~mm}$ deep by $150 \mathrm{~mm}$ (vertically) $200 \mathrm{~mm}$ deep $\times 70 \mathrm{~mm}$.

Note: permission to reprint articles from the IDS Bulletin should be sought from IDS. Contact: Katherine Orme 0273 606261.

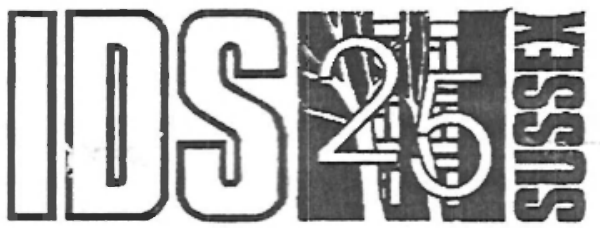

The IDS possesses a unique mailing list in the field of Development Studies - an invaluable marketing asset for books, catalogues and other prom otion material on development economics, politics, rural development, intemational issues etc.

Currently 6,500 names and addresses in 165 countries world-wide, inlcuding research institutes, university libraries, government departments, voluntary agencies, banks and embassies, academics, civil servants and administrators.

A printout (on adhesive labels) of the IDS mailing list can be obtained for $£ 450$ plus postage. Contact: Sarah-Jane Haybittle 0273606261. 


\section{Michael Lipton}

Is deterioration of the environment made worse by the efforts of poor people to become less poor, and by policies to help them do so? Or is poverty itself, partly by increasing people's need for immediate income and hence their reluctance to 'take thought for the morrow', the main cause of environmental damage? Many recent publications ${ }^{2}$ have addressed these questions, either in general or in particular cases. However, such works draw rather little on the disaggregation of nutritional, working, asset-owning, or other aspects of behaviour among poor people between rural and urban, poor and ultra-poor, labourers and farmers, or even women and men. ${ }^{3}$ Partly for this reason, and partly because of the absence of agreed categories and measurements for environmental quality or damage, we have not advanced very far towards answers to the above questions. ror even towards a research agenda to find such answers. This note is an attempt to help formulate sush an agenda.

The systematic analysis of poverty by sociologists and economists, the collection of reasonably reliable evidence, and the improvement of ways to interpret it, have been going $(n$ at least since the publication of the famous Rowntree study of York in 1899. The systematic analy sis of environmental economics, and the collection of relevant evidence about the costs, benefits, and causes of different scales of envirormental gain or loss, are much more recent, at least in the social sciences. It is worth asking whether what we have learned abcut the analysis of poverty - and, even more important, about the effects of attempts to reduce it - has any lessons for the way we approach the analysis of environmental ${ }^{4}$ sustainability.

\footnotetext{
1 This note has benefited cc nsiderably from helpful comments by Melissa Leach. She should not be blamed for what remains.

2 See, for example, J. Leonard, Environment and the Poor, Transaction Books New Brunswick, 1989: P. Dasgupta and K-G. Maler, 'The environment and emerging development issues'. mimeo, WIDER, Helsinki, 1990.

${ }^{3}$ See M. Lipton, The Poor and the Poorest: some Interim Findings, Discussion Paper No. 25, World Bank, Washington, DC, 1988.

4 Of course, it is not only by destroying natural resources - through environmental damage - that a programme to reduce poverty (or to do any other desirable thing) can prove unsustainable. Free midday meals for all school children, designed to reduce malnutrition, proved unsustainable in Andhra Pradesh, India, for fiscal reasons. Many programmes to reduce poverty have been unsustainable administratively.
}

Our knowledge about poverty, and our ability to predict the success or failure of policies against it, has been increased in the past two decades in six ways. First, absolute poverty has been better defined, and separated from the different (though itself important) problem of inequality. For the ultra-poor, it is possible to define a level of calorie intake per day, below which an average person, of a given age, sex, and set of activities or requirements, can function fully and in good health. In different societies and at different price-levels, we can then find the level of expenditure (or income) per person, below which a household runs a sharply increased risk of failing to meet that requirement. At a somewhat higher level of income or expenditure than this 'ultra-poverty line', it is often feasible to identify a level of income below which although calorie requirements are normally met - a household is moderately poor, in the sense that it is very unlikely to add to its human, financial or physical capital thiough net saving.

In many countries and smaller regıons, we can now measure (i) the incidence of poverty in populations (both ultra-poverty and moderate poverty); (ii) the 'intensity' of poverty, i.e. the gap between the income of the average poor person and the minimum requirement to avoid poverty; and (iii) the effect, on the poverty of poor people, of unequal distribution among the poor. There are several sensible ways to "add up' these three components, and hence to measure the severity of poverty. We can then see where, and for whom, poverty is most acute; we can estimate progress in reducing it; and we can compare the effectiveness of anti-porerty programmes.

This is not an empty countirg excrcise. Indeed, we need similarly credible measurements for the extent (inciderce), intensity, and distribution of environmental damage - and of the sustainability or reversibility of the outcomes. It is important, in assigning scarce resources to regions or programmes, or objectives - poverty-reducing or environmentsustaining - to be clear about where and for whom the problem is more severe, and to allocate resources where they are most needed, and/or most cost-effective.

It is also important to be able to identify characteristics of the persons at risk. This is the second area of major progress in poverty analysis. We know, 